\title{
Intraprocedural anticoagulation and postprocedural hemoglobin fall in atrial fibrillation ablation with minimally interrupted direct oral anticoagulants: comparisons across 4 drugs
}

\author{
Akinori Sairaku ${ }^{1}$, Nobuyuki Morishima ${ }^{1}$, Hiroya Matsumura ${ }^{1}$, Michitaka Amioka ${ }^{1}$, Junji \\ Maeda $^{1}$, Yoshikazu Watanabe ${ }^{2}$, and Yukiko Nakano ${ }^{3}$ \\ ${ }^{1}$ Onomichi General Hospital \\ ${ }^{2}$ Hiroshima General Hospital \\ ${ }^{3}$ Hiroshima University
}

June 22, 2020

\begin{abstract}
Background: Thromboembolic or hemorrhagic complications related to atrial fibrillation (AF) ablation are rare, and thus, it is difficult to compare their frequency across different direct oral anticoagulants (DOACs). We aimed to compare the intraablation blood coagulability and postprocedural hemoglobin fall as alternatives to those complications across 4 DOACs. Methods: We enrolled AF patients younger than 65 years old in 3 cardiovascular centers who skipped a single dose of apixaban, dabigatran, edoxaban, and rivaroxaban, prior to the ablation. Endpoints included the activated clotting time (ACT), heparin requirement during the ablation, and drop in the hemoglobin level 24 hours after the procedure. Results: The time-course curves of the ACT differed significantly across the patients with apixaban $(\mathrm{N}=113)$, dabigatran $(\mathrm{N}=130)$, edoxaban $(\mathrm{N}=144)$, and rivaroxaban $(\mathrm{N}=81)$, with its highest level in the dabigatran group $(\mathrm{P}<0.001)$. The average ACT was greater in the dabigatran group than in the other groups $(312.3 \pm 34,334.4 \pm 44,308.1 \pm 41$, and $305.8 \pm 34.7 \mathrm{sec} ; \mathrm{P}<0.001)$. A significant difference was noted in total heparin requirement across the patient groups $(3990.2 \pm 1167.9,3890.4 \pm 955.3,4423.8 \pm 1051.6$, and $3972 \pm 978.7 \mathrm{U} / \mathrm{m} 2 / \mathrm{h}$; $\mathrm{P}<0.001)$, with its greatest amount in the edoxaban group. The reduction in the hemoglobin level was similar $(-0.93 \pm 0.92$, $-0.88 \pm 0.79,-0.89 \pm 0.97,-0.95 \pm 1.23 \mathrm{~g} / \mathrm{dL} ; \mathrm{P}=0.94)$. No inter-group difference was noted in the rate of major or minor bleedings $(0.9 \%, 2.3 \%, 1.4 \%$, and $3.7 \% ; \mathrm{P}=0.51)$, and no thromboembolic events were encountered. Conclusion: A difference in DOACs may have an impact on intraablation anticoagulation, however, it may not on the procedural blood loss in the setting of a single skip.
\end{abstract}

\section{Introduction}

Anticoagulation with direct oral anticoagulants (DOACs) is a corner stone of the periprocedural period of atrial fibrillation (AF) ablation [1]. An uninterrupted DOAC strategy has recently become increasingly common in response to the results of landmark trials [2,3]. Nevertheless, a minimally interrupted DOAC approach still seems to remain a mainstream strategy since a specific antidote for each DOAC is not necessarily available, thus far [1]. Even with a DOAC's short half-live, its unignorable residual activity remains during the ablation procedure with this anticoagulation approach $[4,5]$. Its clinical significance, therefore, may be of interest.

An increasing concern about the procedural safety and operator's dedicated efforts have reduced thromboembolic and hemorrhagic complications during AF ablation, consequently making it difficult to find out any difference in their frequency across the different DOACs [1]. Given that the activated clotting time (ACT) reflects the coagulable state in each subject, and therefore, its measurement is mandatory during the ablation 
[1], it could be worth comparing across the different DOACs instead of thromboembolic events. Unlike major bleeding complications, a significant hemoglobin drop without any overt bleeding is often encountered during the early post-AF ablation period. We thus turned our attention to it as an alternative endpoint to bleeding complications.

The goal of the present study was to test if there was any difference in the parameters regarding intraablation anticoagulation and a post-procedural hemoglobin drop across 4 commercially available DOACs among subjects undergoing AF ablation with a minimally interrupted DOAC approach.

\section{Methods}

\section{Patients}

This is a retrospective and multicenter study of the impact of 4 different minimally interrupted DOACs on the intraprocedural anticoagulation and post-procedural hemoglobin drop following AF ablation. The databases of AF ablation were reviewed in Onomichi General Hospital, Hiroshima General Hospital, and Hiroshima University Hospital. The data from January 2016 to December 2019 were collected. The study protocol was approved by the research committee of each institution. Consecutive patients with AF were considered eligible for inclusion if they underwent a radiofrequency-based pulmonary vein isolation for the first time, and skipped a single dose of apixaban, dabigatran, edoxaban, or rivaroxaban, prior to the ablation procedures. Patients were excluded if they were prescribed with inappropriate DOAC dose regimens, underwent their ablation procedures in the afternoon, or adjunctive ablation procedures such as cavotricuspid isthmus ablation, linear lesions, superior vena cava isolation, or ablation of non-pulmonary vein triggers. Patients who were older than 65 years old were also excluded since a choice of the DOAC was likely to be biased in an elderly population due to safety concerns $[6,7]$.

Blood samples were collected the day before and 24 hours after the ablation in each patient. A complete blood cell count, coagulation markers, and serum chemistry were measured. For risk stratification of thromboembolisms and bleeding, the $\mathrm{CHA}_{2} \mathrm{DS}_{2}$-VASc [8] and ORBID [9] scores were calculated in all patients.

\section{Oral anticoagulation regimens}

The following 4 DOACs had been prescribed at least 4 weeks before the ablation: apixaban, dabigatran, edoxaban, and rivaroxaban. The choice of the DOAC was left to the discretion of each referring physician. On the basis of the current guidelines on the use of DOACs [10] or landmark trials [11-13], the standard doses of apixaban, dabigatran, and edoxaban were determined as $5 \mathrm{mg}$ BID, $150 \mathrm{mg}$ BID, and $60 \mathrm{mg}$ OD, respectively. A landmark trial [14] and the guidelines [10] recommend a $20 \mathrm{mg}$ OD as a standard dose for rivaroxaban. However, based on the J-ROCKET AF trial [15] that included only Japanese patients, its Japan-specific standard dose of $15 \mathrm{mg}$ OD predominated in Japan. The rivaroxaban dose was reduced to 10 $\mathrm{mg}$ OD if the patients had a creatinine clearance of [?]50 ml/min [15]. For apixaban, the reduced dose of 2.5 mg BID was given if patients had 2 of the following 3 factors: age [?]80 years, creatinine [?]1.5 mg/dL, and body weight [?]60 kg [10,11]. To date, there is no pre-specified dose-reduction criteria for dabigatran [10]. In the present study, we considered it an appropriate dose reduction if dabigatran $110 \mathrm{mg}$ BID was prescribed in the patients who were older than 80 years or had a history of massive bleeding [16]. Patients received a lower edoxaban dose of $30 \mathrm{mg}$ OD if they had a creatinine clearance of [?]50 ml/min or body weight [?]60 $\mathrm{kg}[10,13]$. Patients with OD or BID dosing regimens were instructed to take their total or morning dose, respectively, with breakfast. Patients with BID dosing regimens were encouraged to take the evening dose at dinner. On the procedural day, the normal daily dose was not taken until the post-procedural evening in patients with OD dose regimens. The morning dose on the procedural day was skipped, and the evening dose was taken on the post-procedural evening as usual in patients with BID dosing regimens. In the patients prescribed with any antiplatelets, they were withheld for at least 7 days before the procedure. A bridging therapy with heparin was not applied.

\section{Anticoagulation during ablation}

Intraablation anticoagulation was performed on the basis of the current guidelines [1]. An initial heparin 
bolus of 120 units/kg was intravenously administered immediately after the sheath insertion, followed by its continuous infusion of 30-50 units $/ \mathrm{kg} / \mathrm{h}$. Additional heparin boluses were repeated to achieve an ACT of 300-350 sec, if necessary. The ACT was checked at 15-minute intervals with the use of a dedicated analyzer (Hemochron \& Response, International Technidyne Corporation, Edison, NJ, USA) until its target value was achieved, and then at 30-minute intervals for the duration of the procedure. A 20-40 mg dose of protamine was routinely infused to reverse the heparin at the end of the procedure.

\section{Ablation procedure}

The ablation procedures were started in the morning. The details of the double Lasso catheter-guided extensive encircling pulmonary vein antrum isolation performed in this study have been described previously [17]. In brief, 2 decapolar circular catheters were positioned within the ipsilateral superior and inferior pulmonary veins. Circumferential ablation lines were created around the left- and right-sided ipsilateral pulmonary veins with the use of a $3.5 \mathrm{~mm}$-tip irrigated catheter (Thermocool SmartTouch ${ }^{\circledR}$, Biosense Webster, Diamond Bar, CA, USA). Radiofrequency energy was delivered with a maximum power of 30 Watt. Real-time contact force data were used to guide the ablation procedures, with a target force of 10-15 g. The goal of the procedure was to achieve both pulmonary vein entrance and exit block [1].

\section{Endpoints}

The primary endpoints were intraablation anticoagulation parameters including the ACT, time from the initial heparin injection to the first achievement of the target ACT, and heparin requirement. The secondary endpoint was a fall in the hemoglobin level 24 hours after the ablation. The occurrence of major or minor bleeding complications was also measured. Major bleeding complications were defined as the occurrence of a cardiac tamponade, hematoma requiring intervention, hemothorax, or retroperitoneal bleeding. Minor bleeding complications were defined as a hematoma or any bleeding that did not require any intervention or a prolonged hospital stay [18].

\section{Statistical analysis}

The continuous variables were expressed as means \pm standard errors in Figure 4, otherwise as means \pm standard deviation. Categorical variables were summarized as proportions. The differences in the categorical variables across the patient groups were examined with the use of the Pearson Chi-Square test. A one-way analysis of variance was used to compare the normally distributed variables across the groups, and it was followed by a post hoc pairwise comparison with a Tukey-Kramer test. A two-way analysis of variance for repeated measures was used to compare the time-course curves of the ACT. All statistical analyses were performed with the use of JMP software version 13.0 (SAS Institute, Cary, NC, USA). A P value of $<0.05$ was considered significant.

\section{Results}

\section{Patients}

A total of 1639 patients were considered eligible. Among them, 1171 patients met the exclusion criteria: 31 with an inadequate dose reduction of DOACs, 315 with afternoon procedures, 289 with adjunctive ablation procedures, and 861 with an age older than 65 years old. We thus finally studied 468 patients: $113(24.1 \%)$ patients with apixaban, $130(27.8 \%)$ with dabigatran, $144(30.8 \%)$ with edoxaban, and $81(17.3 \%)$ with rivaroxaban. The baseline characteristics of the patients included are summarized in Table 1.

\section{Data on intraprocedural anticoagulation}

The time-course curves of the ACT differed significantly across the patients with apixaban, dabigatran, edoxaban, and rivaroxaban, and its highest levels were seen in the dabigatran group during the time period between the $1^{\text {st }}$ and $4^{\text {th }}$ ACT measurements (Figure 1). The average ACT was greater in the patients with dabigatran than in those with the other DAOCs $(312.3 \pm 34,334.4 \pm 44,308.1 \pm 41$, and $305.8 \pm 34.7$ sec; $\mathrm{P}<0.001$, Figure 2). Time from the initial heparin injection to the first achievement of the target ACT differed significantly across the patient groups (54.8 $\pm 25.6,47.2 \pm 21.6,56.1 \pm 26.8$, and $50.6 \pm 24.1 \mathrm{sec}$; 
$\mathrm{P}=0.02$ ), with its shortest time in the dabigatran group (Figure 2). A significant difference was noted in the total heparin requirement across the patient groups (3990.2 $\pm 1167.9,3890.4 \pm 955.3,4423.8 \pm 1051.6$, and $3972 \pm 978.7 \mathrm{U} / \mathrm{m}^{2} / \mathrm{h} ; \mathrm{P}<0.001$ ), with its greatest amount in the edoxaban group (Figure 3 ).

\section{Fall in the hemoglobin level}

The reduction in the hemoglobin level $(-0.93 \pm 0.92,-0.88 \pm 0.79,-0.89 \pm 0.97,-0.95 \pm 1.23 \mathrm{~g} / \mathrm{dL} ; \mathrm{P}=0.94)$ and its \% reduction $(-6.3 \pm 6.2,-5.8 \pm 5.2,-5.9 \pm 6.3,-6.2 \pm 8.2 \% ; \mathrm{P}=0.93)$ were similar across the patient groups with apixaban, dabigatran, edoxaban, and rivaroxaban (Figure 4).

\section{Complications}

No difference was found in the frequency of major or minor bleeding complications across the patient groups (Table 2). No other serious complications including strokes or death were encountered in the entire study subjects.

\section{Discussion}

\section{Major findings}

The major findings of the present study were twofold. (1) The parameters regarding the intraprocedural anticoagulation differed significantly according to the DOACs that the patients were prescribed even though they were temporarily withheld. (2) There was no difference in the hemoglobin drop following the ablation and rate of bleeding complications across the different DOACs.

\section{More prolonged ACT with dabigatran}

In the present study, we demonstrated that dabigatran prolonged the ACT more than the other DOACs in a setting of a single skip. The possible mechanisms may include (1) dabigatran's more pronounced ability to prolong the ACT, (2) it's greater residual anticoagulant activity, or (3) its tighter positive interaction on the ACT with heparin. Let us discuss each possibility. First, all 4 currently available DOACs have been reported to prolong the ACT [10]. The extent to which a DOAC prolongs the ACT at a certain blood level varies depending on the DOAC. A study [19] reported that dabigatran and rivaroxaban prolonged the ACT in a concentration dependent manner while apixaban necessarily did not. Another extensive study [20] demonstrated that the ACT was longer in the uninterrupted dabigatran arm than in the uninterrupted apixaban and rivaroxaban arms, and a significant positive correlation between the ACT and drug concentration was noted only in the dabigatran arm. These findings may support the first possible mechanism. Second, all 4 DOACs have comparable half-lives [10]. Nevertheless, there are 2 different dosing regimens; edoxaban and rivaroxaban are supposed to be taken once daily while apixaban and dabigatran are given twice a day. In our series, patients with edoxaban and rivaroxaban had regularly taken them in the morning rather than evening according to the Japanese custom. Because of the single skip approach in our series, therefore, their last dose was about 24 hours before the ablation. On the contrary, patients with apixaban and dabigatran took their last dose half a day before the procedure. Accordingly, the blood level of apixaban and dabigatran must have been higher than that of edoxaban and rivaroxaban. The second proposed mechanism may thus be possible. Third, we previously proved in a review article [21] that dabigatran prolongs the ACT in synchronization with heparin. The aforementioned study [20] further showed that the positive interaction on the ACT with heparin was greater with dabigatran than apixaban and rivaroxaban. Therefore, the third mechanism may also be likely.

\section{A greater heparin requirement with edoxaban}

We also showed that the greatest heparin requirement was seen in the edoxaban group. To date, little is known about an interaction between unfractionated heparin and edoxaban. However, we recently demonstrated in a study [22] that there was an inverse correlation between the residual DOAC activity and heparin requirement during AF ablation, and among the 4 DOACs, it was the weakest for edoxaban. That may seemingly be in line with the finding, and possibly suggest edoxaban's weaker interaction with heparin. 


\section{Clinical implications}

The present study is among a few studies comparing 4 different minimally interrupted DOACs. In particular, data on edoxaban is scant. We thus believe that our findings may be helpful for understanding the characteristics of each DOAC. Also, the equality of the blood loss across the 4 DOACs shown in the present study may be of value in terms of the procedural safety.

\section{Limitations}

We excluded elderly subjects. The reproducibility of $\mathrm{ACT}$ is generally somewhat questionable. The present study was a retrospective one.

\section{Funding}

This work was not supported by any external funding.

\section{Conflict of interest}

None declared.

\section{References}

1. Calkins H, Hindricks G, Cappato R, Kim YH, Saad EB, Aguinaga L, Akar JG, Badhwar V, Brugada J, Camm J, Chen PS, Chen SA, Chung MK, Cosedis Nielsen J, Curtis AB, Davies DW, Day JD, d'Avila A, Natasja de Groot NMS, Di Biase L, Duytschaever M, Edgerton JR, Ellenbogen KA, Ellinor PT, Ernst S, Fenelon G, Gerstenfeld EP, Haines DE, Haissaguerre M, Helm RH, Hylek E, Jackman WM, Jalife J, Kalman JM, Kautzner J, Kottkamp H, Kuck KH, Kumagai K, Lee R, Lewalter T, Lindsay BD, Macle L, Mansour M, Marchlinski FE, Michaud GF, Nakagawa H, Natale A, Nattel S, Okumura K, Packer D, Pokushalov E, Reynolds MR, Sanders P, Scanavacca M, Schilling R, Tondo C, Tsao HM, Verma A, Wilber DJ, Yamane T; Document Reviewers:. 2017 HRS/EHRA/ECAS/APHRS/SOLAECE expert consensus statement on catheter and surgical ablation of atrial fibrillation. Europace. 2018;20:e1-e160.

2. Cappato R, Marchlinski FE, Hohnloser SH, Naccarelli GV, Xiang J, Wilber DJ, Ma CS, Hess S, Wells DS, Juang G, Vijgen J, Hügl BJ, Balasubramaniam R, De Chillou C, Davies DW, Fields LE, Natale A; VENTURE-AF Investigators. Uninterrupted rivaroxaban vs. uninterrupted vitamin $\mathrm{K}$ antagonists for catheter ablation in non-valvular atrial fibrillation. Eur Heart J. 2015;36:1805-11.

3. Calkins H, Willems S, Gerstenfeld EP, Verma A, Schilling R, Hohnloser SH, Okumura K, Serota H, Nordaby M, Guiver K, Biss B, Brouwer MA, Grimaldi M; RE-CIRCUIT Investigators. Uninterrupted Dabigatran versus Warfarin for Ablation in Atrial Fibrillation. N Engl J Med. 2017;376:1627-1636.

4. Godier A, Dincq AS, Martin AC, Radu A, Leblanc I, Antona M, Vasse M, Golmard JL, Mullier F, Gouin-Thibault I. Predictors of pre-procedural concentrations of direct oral anticoagulants: a prospective multicentre study. Eur Heart J. 2017;38:2431-2439.

5. Sairaku A, Nakano Y, Onohara Y, Hironobe N, Matsumura H, Shimizu W, Kihara Y. Residual anticoagulation activity in atrial fibrillation patients with temporary interrupted direct oral anticoagulants: Comparisons across 4 drugs. Thromb Res. 2019;183:119-123.

6. Mueller T, Alvarez-Madrazo S, Robertson C, Wu O, Bennie M. Comparative safety and effectiveness of direct oral anticoagulants in patients with atrial fibrillation in clinical practice in Scotland. Br $\mathrm{J}$ Clin Pharmacol. 2019;85:422-431.

7. Silverio A, Di Maio M, Prota C, De Angelis E, Radano I, Citro R, Carrizzo A, Ciccarelli M, Vecchione C, Capodanno D, Galasso G. Safety and efficacy of non-vitamin K antagonist oral anticoagulants in elderly patients with atrial fibrillation. Eur Heart J Cardiovasc Pharmacother. 2019 Dec 12. Online ahead of print.

8. Lip GY, Nieuwlaat R, Pisters R, Lane DA, Crijns HJ. Refining clinical risk stratification for predicting stroke and thromboembolism in atrial fibrillation using a novel risk factor-based approach: the euro heart survey on atrial fibrillation. Chest. 2010;137:263-72.

9. O'Brien EC, Simon DN, Thomas LE, Hylek EM, Gersh BJ, Ansell JE, Kowey PR, Mahaffey KW, Chang P, Fonarow GC, Pencina MJ, Piccini JP, Peterson ED. The ORBIT bleeding score: a simple 
bedside score to assess bleeding risk in atrial fibrillation. Eur Heart J. 2015;36:3258-64.

10. Steffel J, Verhamme P, Potpara TS, Albaladejo P, Antz M, Desteghe L, Haeusler KG, Oldgren J, Reinecke H, Roldan-Schilling V, Rowell N, Sinnaeve P, Collins R, Camm AJ, Heidbüchel H; ESC Scientific Document Group. The 2018 European Heart Rhythm Association Practical Guide on the use of non-vitamin $\mathrm{K}$ antagonist oral anticoagulants in patients with atrial fibrillation. Eur Heart J. 2018;39:1330-1393.

11. Granger CB, Alexander JH, McMurray JJ, Lopes RD, Hylek EM, Hanna M, Al-Khalidi HR, Ansell J, Atar D, Avezum A, Bahit MC, Diaz R, Easton JD, Ezekowitz JA, Flaker G, Garcia D, Geraldes M, Gersh BJ, Golitsyn S, Goto S, Hermosillo AG, Hohnloser SH, Horowitz J, Mohan P, Jansky P, Lewis BS, Lopez-Sendon JL, Pais P, Parkhomenko A, Verheugt FW, Zhu J, Wallentin L; ARISTOTLE Committees and Investigators. Apixaban versus warfarin in patients with atrial fibrillation. N Engl J Med. 2011;365:981-92.

12. Connolly SJ, Ezekowitz MD, Yusuf S, Eikelboom J, Oldgren J, Parekh A, Pogue J, Reilly PA, Themeles E, Varrone J, Wang S, Alings M, Xavier D, Zhu J, Diaz R, Lewis BS, Darius H, Diener HC, Joyner CD, Wallentin L; RE-LY Steering Committee and Investigators. Dabigatran versus warfarin in patients with atrial fibrillation. N Engl J Med. 2009;361:1139-51.

13. Giugliano RP, Ruff CT, Braunwald E, Murphy SA, Wiviott SD, Halperin JL, Waldo AL, Ezekowitz MD, Weitz JI, Špinar J, Ruzyllo W, Ruda M, Koretsune Y, Betcher J, Shi M, Grip LT, Patel SP, Patel I, Hanyok JJ, Mercuri M, Antman EM; ENGAGE AF-TIMI 48 Investigators. Edoxaban versus warfarin in patients with atrial fibrillation. N Engl J Med. 2013;369:2093-104.

14. Patel MR, Mahaffey KW, Garg J, Pan G, Singer DE, Hacke W, Breithardt G, Halperin JL, Hankey GJ, Piccini JP, Becker RC, Nessel CC, Paolini JF, Berkowitz SD, Fox KA, Califf RM; ROCKET AF Investigators. Rivaroxaban versus warfarin in nonvalvular atrial fibrillation. $\mathrm{N}$ Engl J Med. 2011;365:883-91.

15. Hori M, Matsumoto M, Tanahashi N, Momomura S, Uchiyama S, Goto S, Izumi T, Koretsune Y, Kajikawa M, Kato M, Ueda H, Iwamoto K, Tajiri M; J-ROCKET AF study investigators. Safety and efficacy of adjusted dose of rivaroxaban in Japanese patients with non-valvular atrial fibrillation: subanalysis of J-ROCKET AF for patients with moderate renal impairment. Circ J. 2013;77:632-8.

16. Farmakis D, Davlouros P, Giamouzis G, Giannakoulas G, Pipilis A, Tsivgoulis G, Parissis J. Direct Oral Anticoagulants in Nonvalvular Atrial Fibrillation: Practical Considerations on the Choice of Agent and Dosing. Cardiology. 2018;140:126-132.

17. Watanabe R, Sairaku A, Yoshida Y, Nanasato M, Kamiya H, Suzuki H, Ogura Y, Aoyama Y, Maeda M, Ando M, Eguchi S, Inden Y, Kihara Y, Murohara T. Head-to-head comparison of acute and chronic pulmonary vein stenosis for cryoballoon versus radiofrequency ablation. Pacing Clin Electrophysiol. 2018;41:376-382.

18. Di Biase L, Burkhardt JD, Santangeli P, Mohanty P, Sanchez JE, Horton R, Gallinghouse GJ, Themistoclakis S, Rossillo A, Lakkireddy D, Reddy M, Hao S, Hongo R, Beheiry S, Zagrodzky J, Rong B, Mohanty S, Elayi CS, Forleo G, Pelargonio G, Narducci ML, Dello Russo A, Casella M, Fassini G, Tondo C, Schweikert RA, Natale A. Periprocedural stroke and bleeding complications in patients undergoing catheter ablation of atrial fibrillation with different anticoagulation management: results from the Role of Coumadin in Preventing Thromboembolism in Atrial Fibrillation (AF) Patients Undergoing Catheter Ablation (COMPARE) randomized trial. Circulation. 2014;129:2638-44.

19. Ebner M, Birschmann I, Peter A, Spencer C, Härtig F, Kuhn J, Blumenstock G, Zuern CS, Ziemann U, Poli S. Point-of-care testing for emergency assessment of coagulation in patients treated with direct oral anticoagulants. Crit Care. 2017;21:32.

20. Martin AC, Kyheng M, Foissaud V, Duhamel A, Marijon E, Susen S, Godier A. Activated Clotting Time Monitoring during Atrial Fibrillation Catheter Ablation: Does the Anticoagulant Matter? J Clin Med. 2020;9:350.

21. Sairaku A, Nakano Y, Kihara Y. Does dabigatran interfere with intraablation heparinization? Thromb Res. 2014;134:742-3.

22. Sairaku A, Onohara Y, Hironobe N, Matsumura H, Kihara Y, Nakano Y. Remaining activity of tempo- 
rary interrupted direct oral anticoagulants and its impact on intra-ablation heparinization in patients with atrial fibrillation: Comparisons across four drugs and two dose regimens. J Cardiovasc Electrophysiol. 2020 May 27. Online ahead of print.

\section{Figure legends}

Figure 1. The time-course of the activated clotting time (ACT). The numbers below the horizontal axis indicate the number of times in which the ACT was measured. The means are presented.

Figure 2. The average activated clotting time (ACT) and time from the initial heparin injection to the first achievement of the target ACT. The means and standard deviations are presented. ${ }^{*} \mathrm{P}<0.001$ versus dabigatran, ${ }^{+} \mathrm{P}=0.02$ versus dabigatran.

Figure 3. The total heparin requirement during the ablation procedure. The means and standard deviations are presented. ${ }^{*} \mathrm{P}<0.001$ versus edoxaban, ${ }^{+} \mathrm{P}<0.01$ versus edoxaban.

Figure 4. Change and percent change in the hemoglobin level before and 24 hours after the atrial fibrillation ablation. The means and standard errors are presented.

\section{Hosted file}

table 1 20200607.xlsx available at https://authorea.com/users/335145/articles/461028intraprocedural-anticoagulation-and-postprocedural-hemoglobin-fall-in-atrialfibrillation-ablation-with-minimally-interrupted-direct-oral-anticoagulants-comparisonsacross-4-drugs

\section{Hosted file}

table 2 20200618.xlsx available at https://authorea.com/users/335145/articles/461028intraprocedural-anticoagulation-and-postprocedural-hemoglobin-fall-in-atrialfibrillation-ablation-with-minimally-interrupted-direct-oral-anticoagulants-comparisonsacross-4-drugs

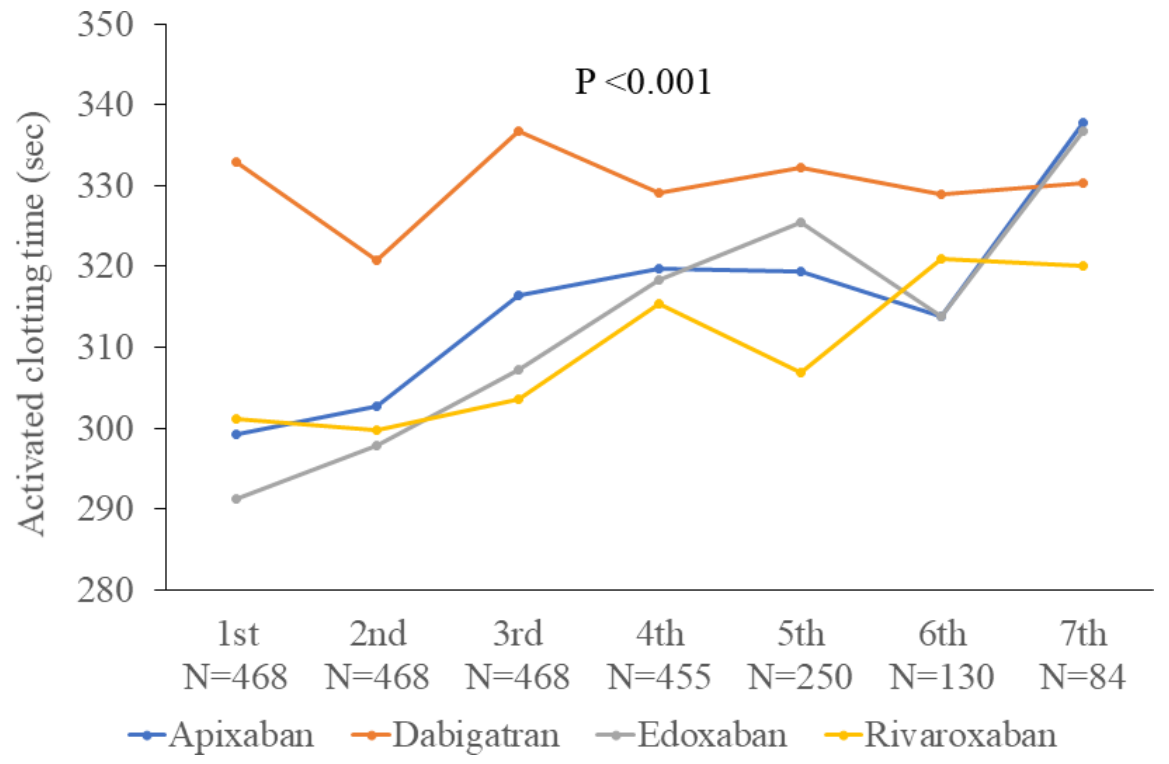




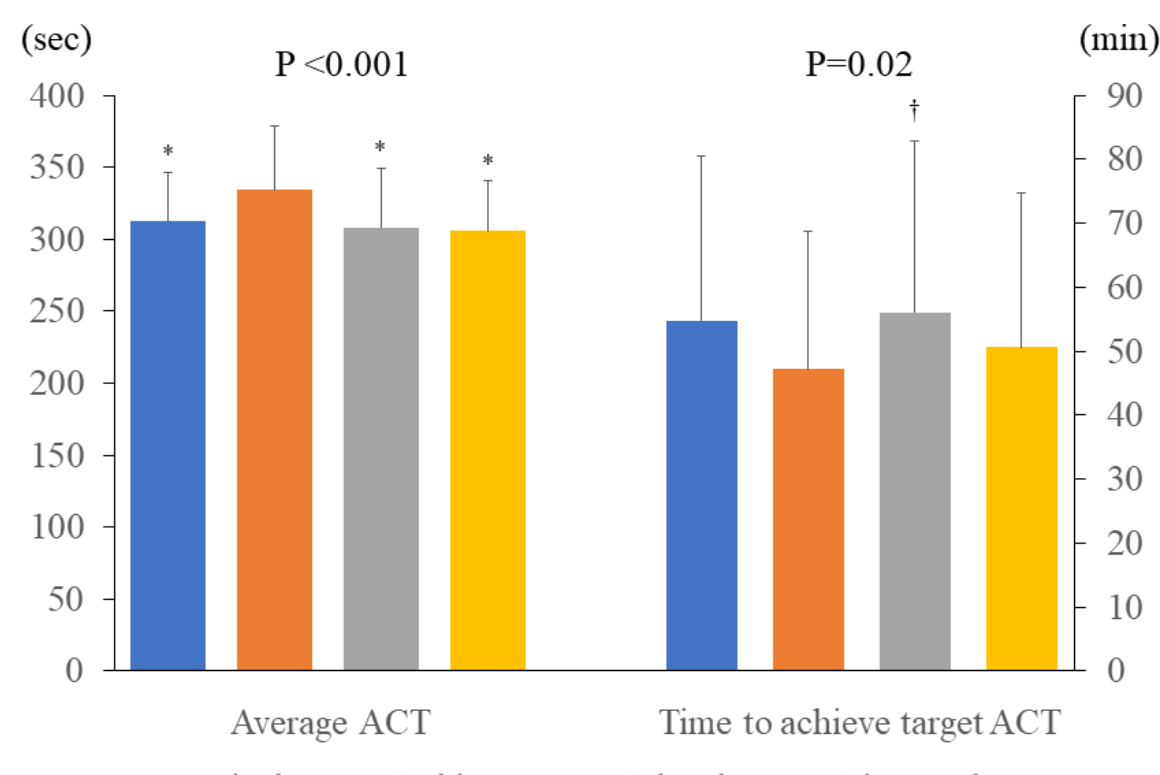

- Apixaban Dabigatran Edoxaban $\square$ Rivaroxaban

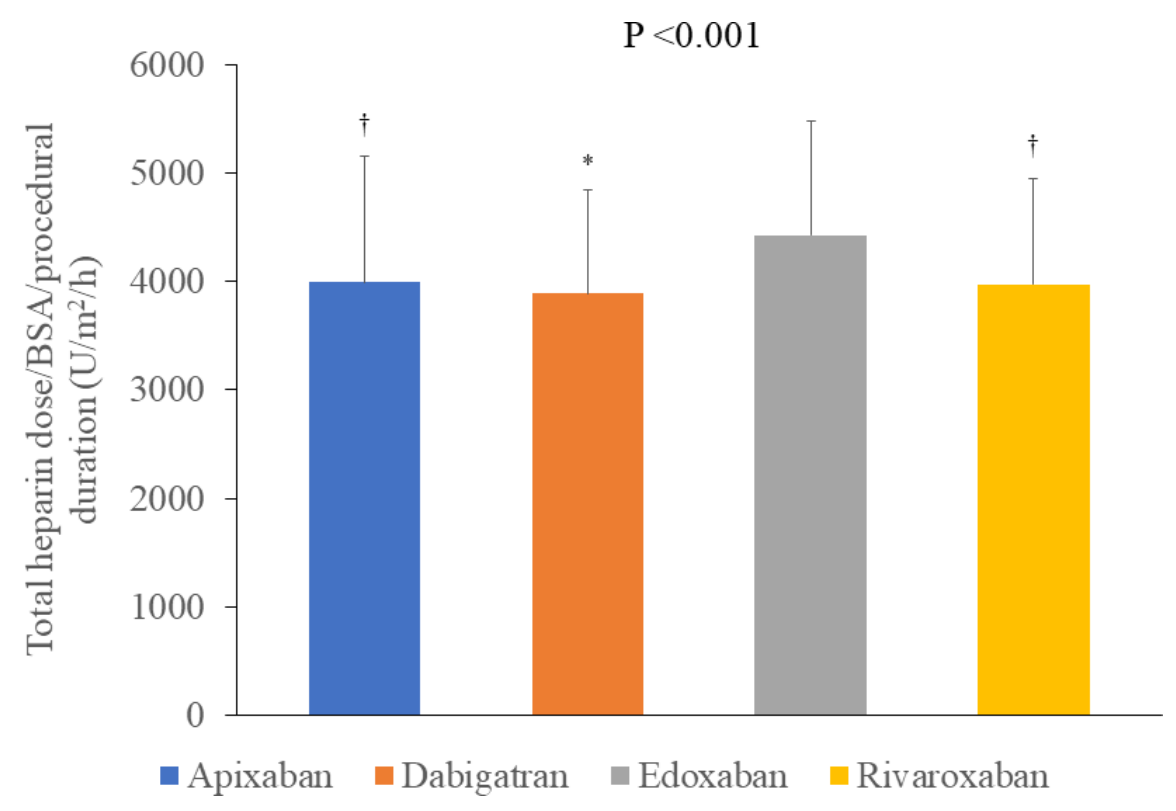




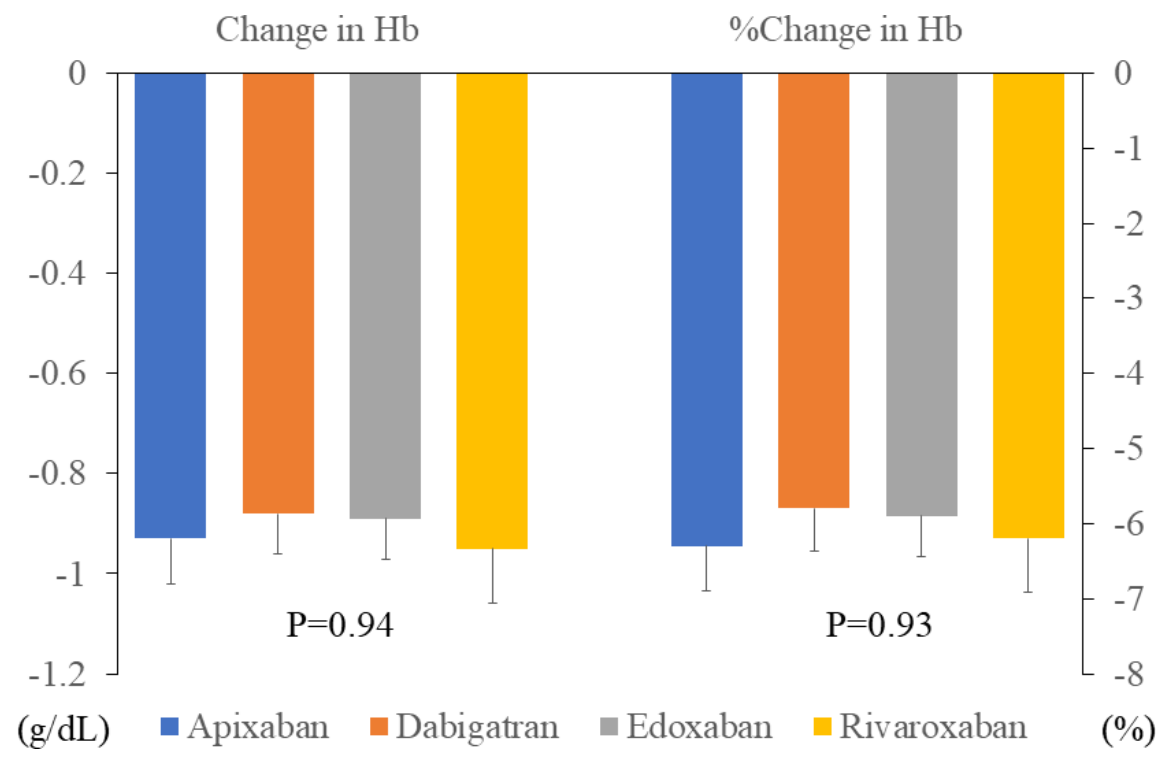

